\title{
Bile duct stone caused by 25-year placement of metal stent: successful diagnosis and extraction using peroral cholangioscopy
}

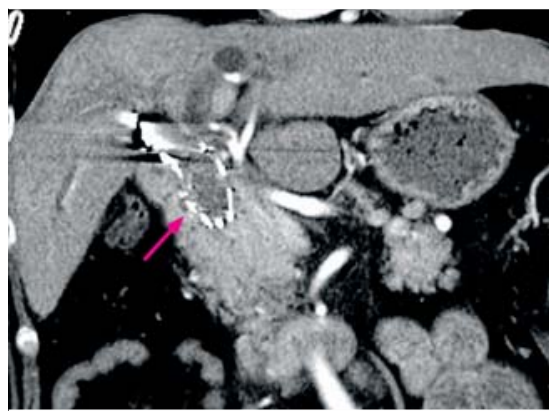

- Fig. 1 Computed tomography findings. A mass lesion was found inside the metal stent (pink arrow).

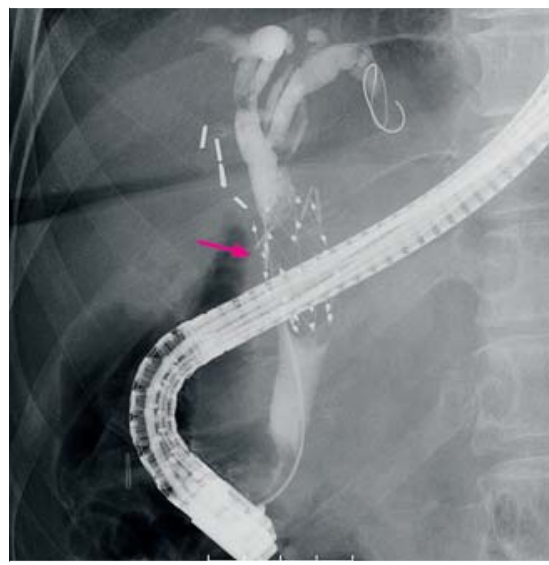

- Fig. 2 Endoscopic retrograde cholangiopancreatography findings. Cholangiography showed a filling defect inside the metal stent (pink arrow).

Bile duct stones can form when a foreign body (e.g. metal stent) is placed for a long period. We report the case of a bile duct stone caused by a metal stent that had been in place for 25 years.

A 61-year-old woman underwent detailed tests for obstructive jaundice at our hospital. Approximately 25 years previously, she had undergone cholecystectomy for a gallbladder stone at a different hospital, followed by percutaneous placement of a metal stent (Gianturco-Rosch biliary Z-stent; Cook Medi-

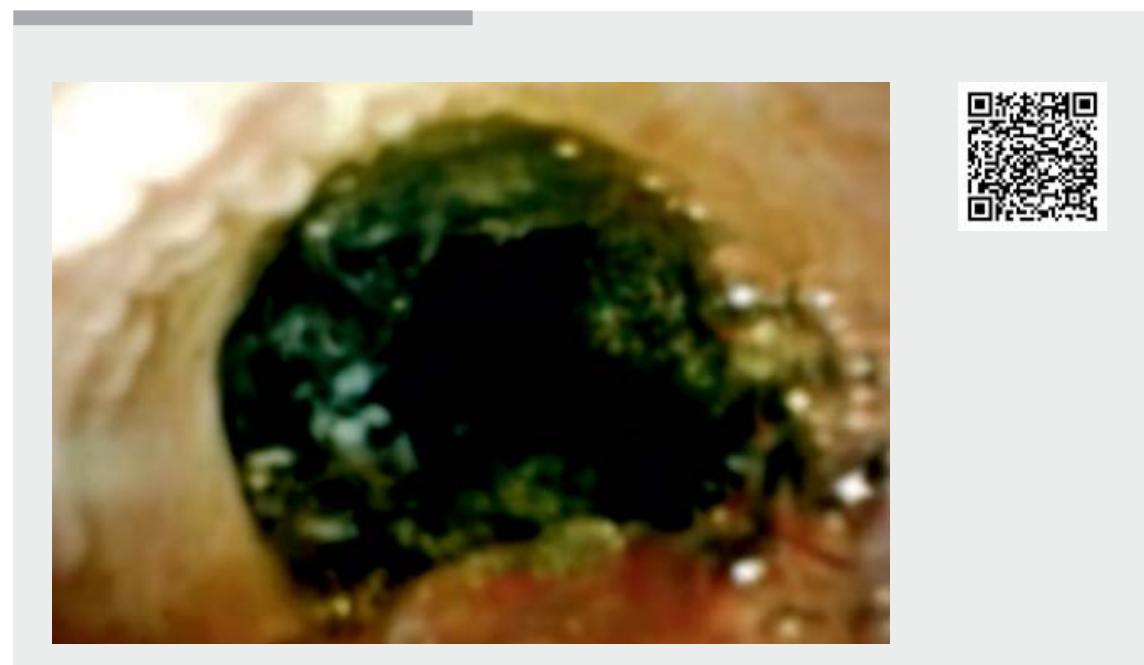

Video 1 A bile duct stone occupying the metal stent was fragmented using a 1.9-Fr electrohydraulic lithotripsy probe. Fragments were removed using a balloon catheter, resulting in resolution of the stenosis inside the metal stent.

cal, Inc., Bloomington, Indiana, USA) for postoperative bile duct stenosis [1]. Contrast-enhanced computed tomography showed a mass lesion inside the metal stent; this was considered to be the cause of the jaundice ( $\triangleright$ Fig. 1). Endoscopic retrograde cholangiopancreatography was then conducted for additional tests and treatment.

Cholangiography showed a filling defect

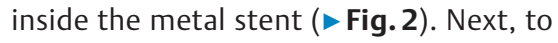
distinguish between a tumor and bile duct stone, peroral cholangioscopy (POCS) was conducted using SpyGlass DS (Boston Scientific Corp., Marlborough, Massachusetts, USA) ( Video 1) [2-4]. A bile duct stone was found to occupy the metal stent, and electrohydraulic lithotripsy (EHL) was conducted using a 1.9-Fr EHL probe, followed by removal of the stone using a balloon catheter ( $\triangleright$ Fig.3). Removal of the stone resulted in resolution of the stenosis inside the metal stent ( $\triangleright$ Fig.4), and the patient recovered from jaundice; hence, this patient is now observed on an outpatient basis.

This report of obstructive jaundice caused by a bile duct stone in a metal stent that had been in place for 25 years, illustrates how POCS can be used to identify the cause of jaundice and aid removal of the stone using EHL. It was possible to visualize the effects of long term metal stent placement directly using POCS.

Endoscopy_UCTN_Code_CPL_1AK_2AH

Competing interests

None

The authors

Yuki Tanisaka, Shomei Ryozawa, Masafumi Mizuide, Akashi Fujita, Tomoya Ogawa Department of Gastroenterology, Saitama Medical University International Medical Center, Saitama, Japan 

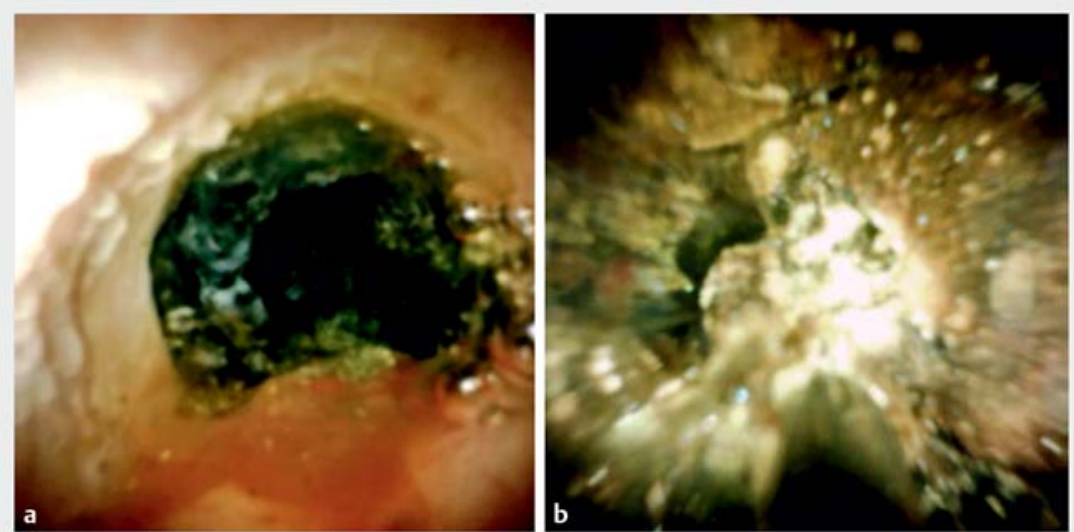

- Fig. 3 Peroral cholangioscopy findings. a A bile duct stone was found to occupy the metal stent. b Electrohydraulic lithotripsy was carried out.

Corresponding author

\section{Yuki Tanisaka MD, PhD}

Department of Gastroenterology, Saitama Medical University International Medical

Center, 1397-1 Yamane, Hidaka, Saitama 350-1298, Japan

Fax: +81-42-9844589

tanisaka1205@gmail.com

\section{References}

[1] Irving JD, Adam A, Dick R et al. Gianturco expandable metallic biliary stents: results of a European clinical trial. Radiology 1989; 172: $321-326$

[2] Navaneethan U, Hasan MK, Kommaraju K et al. Digital, single-operator cholangiopancreatoscopy in the diagnosis and management of pancreatobiliary disorders: a multi- center clinical experience (with video). Gastrointest Endosc 2016; 84: 649-655

[3] Shah R], Raijman I, Brauer B et al. Performance of a fully disposable, digital, singleoperator cholangiopancreatoscope. Endoscopy 2017; 49: 651-658

[4] Ogura T, Imanishi M, Kurisu Y et al. Prospective evaluation of digital single-operator cholangioscope for diagnostic and therapeutic procedures (with videos). Dig Endosc 2017; 29: 782-789

\section{Bibliography}

DOI https://doi.org/10.1055/a-1067-4299

Published online: 9.12.2019

Endoscopy 2020; 52: E193-E194

(c) Georg Thieme Verlag KG

Stuttgart · New York

ISSN 0013-726X

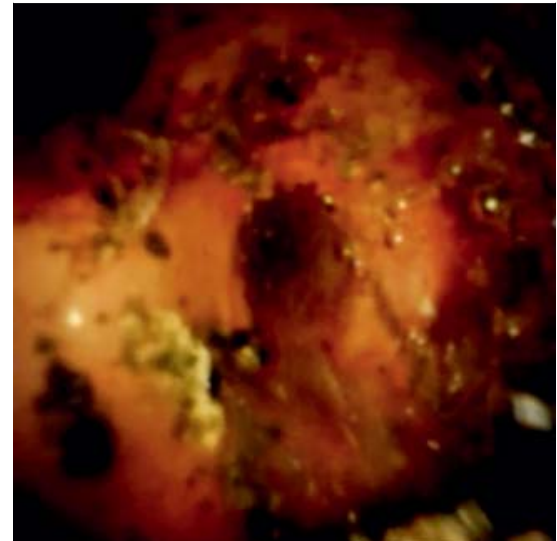

Fig. 4 Peroral cholangioscopy findings. Removal of the stone resulted in resolution of the stenosis inside the metal stent.

\section{ENDOSCOPY E-VIDEOS}

https://eref.thieme.de/e-videos

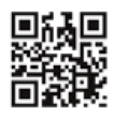

Endoscopy E-Videos is a free access online section, reporting on interesting cases and new techniques in gastroenterological endoscopy. All papers include a high quality video and all contributions are freely accessible online.

This section has its own submission website at

https://mc.manuscriptcentral.com/e-videos 